\title{
Comunidad Andina y negocios internacionales: una visión desde su institucionalidad y supranacionalidad
}

FECHA DE RECEPCIÓN: 23 de agosto FECHA DE APROBACIÓN: 17 de octubre Pp. 70-85

The Andean institutionalism

and supranationalism

for agreements and

international trade

\section{Institutionnalité et}

supranationalité andine pour les

traités et le commerce

international

Institucionalidade $\boldsymbol{E}$

supranacionalidade andina

para os acurdos e a comércio

internacional

\section{Luis Nelson Beltrán Mora*}

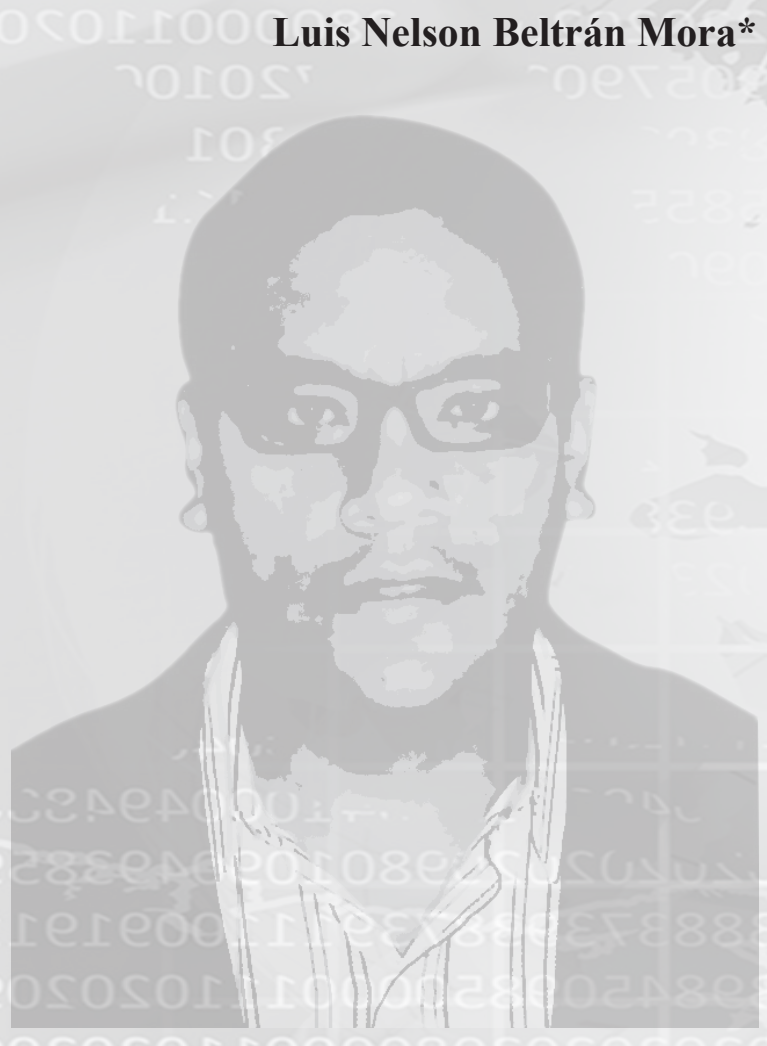

*PhD en Integración y desarrollo económico de la Universidad Autónoma de Madrid-UAM-, y candidato a Doctor en Derecho internacional y relaciones internacionales del Instituto de Investigaciones Ortega y Gasset y la Universidad Complutense de Madrid; Investigador principal de la Escuela de Marketing y Publicidad de la Universidad Sergio Arboleda. 


\section{RESUMEN}

Este trabajo, presenta la evolución de la integración de la Comunidad Andina (CAN) desde la perspectiva del derecho internacional; se deduce que el Sistema de Integración Andino (SAI), no sólo ha permitido la promoción de los negocios sino que el Derecho Comunitario (DC) desarrollado en el grupo, blinda los tratados comerciales dando institucionalidad y supranacionalidad a la $C A N$, al punto de convertirse en referencia para imitarlo en la reciente creada Unión de Naciones del Sur (UNASUR). En la CAN, el nuevo regionalismo abierto genera incertidumbre sobre el futuro de dicho bloque.

s.

\section{$(45$}

Negocios internacionales

Comunidad Andina (CAN)

Acuerdo de Cartagena

Unión de Naciones del Sur

(UNASUR)

Derecho internacional

Derecho Comunitario

Tribunal Andino de Fusticia (TAF).

\section{ABSTRACT}

This article shows the evolution of the integration of the Andean Community (CAN) from an International Law perspective. It is inferred that the Andean Integration System (SAI) has not only promoted business, but also the DC community's right law applied by this group, limiting trade agreements and giving institutionalism and supranationalism to $C A N$ organization, becoming a point of reference for the recent creation of the South American Nations Union (UNASUR). At CAN, the new open regionalism creates uncertainty about the future of this organization.

\section{RESUMÉÉ}

Cet article présente les évolutions de la CAN (Communauté Andine des Nations) en matière d'intégration du droit international et montre que le système d'intégration andin (SAI) a non seulement permis le succès de l'entreprise, mais que le droit communautaire (DC) mis en place par le groupe de nation renforce les accords commerciaux en institutionnalisant la CAN comme référence à imiter par la récente Union des Nations du Sud (UNASUR). Au sein de la CAN, le nouveau regain de régionalisme génère des incertitudes sur l'avenir de la Communauté.

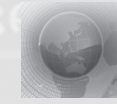

\section{Key words}

International business

The Andean Community $(C A N)$

The Cartagena agreement

The South American

Nations Union (UNASUR)

International right

Community right

The Andean Fudicial Board

(TAF)

\section{Mots clefs}

Commerce International

Communauté Andine des

Nations (CAN) Accord

de Carthagène Union des

Nations du Sud (UNASUR)

Droit International

Droit Communautaire

Cour de Fustice des États Andins (TAF).

\section{RESUMO}

Este trabalho apresenta a evolução da integração da Comunidade Andina CAN desde a perspectiva do Direito Internacional; mostra-se que o Sistema de Integração Andino $S A I$, não só permitiu a promoção dos negócios, mas também que o direito comunitário $D C$ desenvolvido no grupo, protege os acordos comerciais dando à CAN institucionalidade e supranacionalidade; até o ponto de tornar-se a referência para imitação na recentemente criada União de Nações do Sul (UNASUR). Na CAN o novo regionalismo aberto gera incerteza sobre o futuro deste bloco.

\section{Palavras-chave}

Negócios internacionais

Comunidade Andina

(CAN) Acordo de Cartagena

União de Nações do Sul

(UNASUR) Direito

Internacional

Direito Comunitário

Tribunal Andino de Fustiça

(TAF) 


\section{INTRODUCCIÓN}

$\mathrm{U}$ no de los procesos de integración económica más importante en América Latina, es el de la región andina, que nació con el nombre de Grupo Andino (GRAN) en 1969, mediante la firma del Acuerdo de Cartagena y que tomó el nombre de Comunidad Andina (CAN) en 1996. Los países que integraron el GRAN fueron en principio Colombia, Ecuador, Perú y Chile; Venezuela se adhirió en 1973; en 1976, se retiró del grupo Chile y en abril de 2006, dimitió Venezuela; en noviembre de 2006, otra vez Chile solicitó su admisión al grupo y fue aceptado como observador, quedando pendiente y muy próxima su reincorporación como socio pleno.

La CAN, cuando contaba con los cinco países andinos, presentó resultados interesantes; hasta 2012, los flujos comerciales intragrupo aumentaron más de 90 veces desde su creación, superando los incrementos de los bloques como Nafta $^{1}$ y Mercosur. En 2005, el comercio de bienes llegó a US $\$ 10.000$ millones y los flujos de capital representaron cerca del $20 \%$ de los intercambios. No obstante, los economistas vienen hablando en torno a que los resultados se han producido entre otros factores, por la vecindad geográfica, la ventaja comparativa y la especialización de la producción de cada uno de los países, como el no pago de aranceles para más del $90 \%$ de los intercambios; poco se ha analizado la institucionalidad y la normativa jurídica de la CAN, factores que no sólo han contribuido a darle seguridad jurídica a los negocios entre sus socios, sino que más importante, han relanzado la integración andina a áreas en los frentes político, social y cultural. El marco normativo de la CAN, se considera como el más avanzado en derecho público internacional en América Latina, comparable sólo con el derecho comunitario de la Unión Europea (UE) (Kassin, 2005).

Este artículo, está divido en dos grandes ítems: en el primero, se hace un breve balance del proceso de globalización e integración de la CAN, observando la evolución y dinámica de su institucionalidad normativa, en comparación con los desarrollos de la UE. En el segundo ítem, se pone de manifiesto los conceptos de integración regional y supranacionalidad en las constituciones políticas de los países andinos y la importancia del Tribunal Andino de Justicia (TAJ), para hacer cumplir los preceptos comunitarios, como órgano jurisdiccional de la región; además, que tiene por competencias, entre otras de conocer y resolver las acciones de nulidad, de los incumplimientos, de la interpretación prejudicial y del arbitraje entre sus socios. Se profundiza en aspectos como los principios del ordenamiento jurídico, en cuanto a su preeminencia, aplicabilidad y efecto directo, factores todos que garantizan la integración y la supranacionalidad del grupo; finalmente, se termina con algunas conclusiones y recomendaciones sobre el futuro de la CAN y su ordenamiento judicial en el espacio suramericano.

\footnotetext{
${ }^{1}$ Tratado de libre comercio entre Estados Unidos, México y Canadá.
} 


\section{GLOBALIZACIÓN E INSTITUCIONALIDAD ANDINA.}

ᄃ

os análisis sobre los logros de la integración andina en materia económica, siempre se han apoyado en lo que comercialmente ha logrado el grupo; poco se ha estudiado el marco institucional y normativo, con lo que está construida la CAN y la influencia que ellos han tenido en los negocios de la región y en la arquitectura de la misma organización.

Los procesos de integración apoyados hoy en el concepto de globalización ${ }^{2}$, plantean varios estadios para impulsar la integración y asociación entre economías. La teoría de la in-

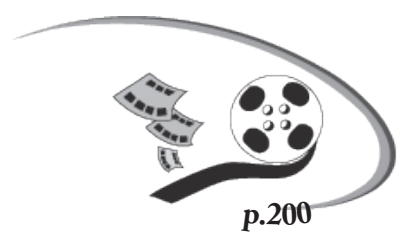

tegración económica, habla de realizar

zonas de libre comercio, aranceles

externos comunes, mercados comunes

y sociedades económicas. Cada vez que se avance en una de estas etapas, la integración será más

plena y de compromisos más serios entre los socios, toda vez que se va requiriendo del derecho internacional para disminuir los riesgos en los flujos de bienes y servicios (Beltrán, 2008). En la primera etapa, significa que los países firmantes de los tratados no se cobran aranceles para los bienes con valor agregado de los países de origen que hacen parte de los tratados; además, que se disminuyen las barreras para-arancelarías con el fin de que circulen libremente las mercancías.

El arancel externo común, significa que los países socios, además de reducir los aranceles entre ellos, establecen uno común para el resto de países que no están dentro del acuerdo; en este estadio, lo que se quiere evitar es la triangulación de mercancías, porque se considera que los nuevos acuerdos perforan los tratados pre-existentes. En el mercado común, los países además de establecer la zona de libre comercio y el arancel externo común, liberan los mercados laborales y de capitales, estableciendo políticas de fomento común para el intercambio dentro del grupo. El proceso de integración más avanzado, es la sociedad económica, donde los países miembros compatibilizan la política macroeconómica en materias como fiscal, monetaria y cambiaria. En la historia de la integración y el comercio mundial, el proceso hacia la sociedad económica, lo ha experimentado la Comunidad Europea (CE), hoy llamada Unión Europea (UE). Este bloque, con la entrada en vigencia del acuerdo de Maastricht (1993), está llegando a la unión monetaria. La UE, está avanzando en la propuesta para el nacimiento de una sola constitución política en el grupo, con el fin de perfeccionar la integración económica; este bloque, es una verdadera comunidad en materia de integración en el sentido que el Euro, que entró en vigencia en 1999, es la moneda común; así mismo, los participantes acatan fielmente las políticas de aranceles entre ellos y con terceros y dentro de la UE, los países cumplen con las metas macro-económicas impuestas, entre las que se destacan los indicadores de un solo digito para el déficit fiscal, la inflación y las tasas de interés 3 .

La CAN, es un bloque regional que ha avanzado también desde 1969 por lograr una integración plena entre sus participantes, al punto que perfeccionando los acuerdos, ha pasado de la zona de libre comercio en dicho año, a un arancel externo común imperfecto en 1994 y la propuesta de un mercado común en el nuevo milenio; sin estos acuerdos, sería difícil pensar en la evolución de los intercambios de bienes y servicios dentro del grupo (Beckerman, 2005).

El dinamismo del comercio de la CAN, no se puede así atribuir solamente a la vecindad geográfica, al aprovechamiento de las ventajas comparativas en la producción de recursos naturales, o al propio desempeño de las economías, toda vez que el marco institucional y normativo, ha jugado un papel de suma importancia en la arquitectura y evolución de la integración económica. En la encuesta de competitividad andina realizada por la Cámara Colombo Venezolana en Bogotá, en mayo de 2005 y reforzado en la encuesta

\footnotetext{
${ }^{2}$ El FMI define la globalización económica como la libre circulación de bienes, servicios, tecnología y capitales, cuyos agentes principales son las empresas transnacionales (FMI, 2002).

${ }^{3}$ Para un mejor conocimiento en integración y estructura de la integración, véase el trabajo del profesor Tamales, sobre estructura de la integración europea, Madrid, 2003.
} 
realizada en 2009 (U. Salle, 2009) a un grupo de expertos en comercio internacional, a la pregunta sobre determinantes del comercio, se concluye que el $85 \%$ y $87 \%$ de los encuestados ven en la conformación de los tratados y la seguridad jurídica, los instrumentos más importantes para mantener las expectativas, la confianza y la realización de los negocios dentro del área regional. Este indicador, supera los porcentajes de favorabilidad del crecimiento, de la vecindad y de la complementación económica (Covenotas, 2005; U Salle, 2009).

En efecto, el nacimiento del GRAN en 1969, hizo que en la década de los 70 el comercio de la CAN se incrementará tres veces; luego, la entrada en vigencia del arancel externo común en 1994, produjo un aumento del comercio de cinco veces, en relación con la década de los 80 ; finalmente, la idea en torno a comenzar a trabajar en un mercado común en 2000, coincidió con un aumento de flujos de comercio de tres veces, entre 2001 y 2006 (Beltrán, 2006).

En definitiva, los acuerdos en materia de integración, lograron que los intercambios de la región pasaran de US\$300 millones en 1969, a la suma de US\$8.000 millones en 2005 y que las inversiones directas intragrupo, superaran los US $\$ 1.000$ millones anuales entre 2000 y 2010 (Figura 1).

\section{Figura 1. Comercio andino}

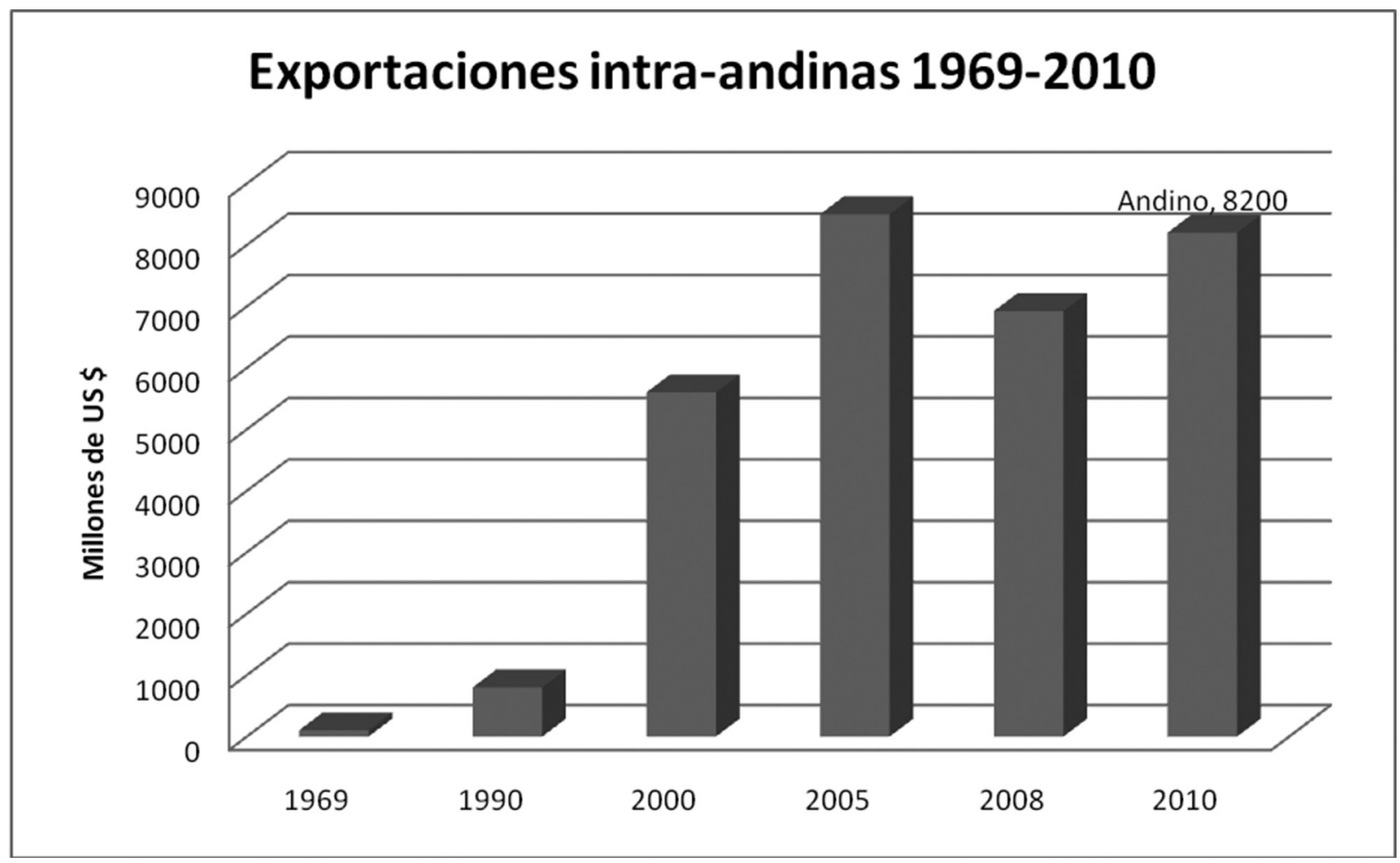

Fuente. Elaborado por el autor, con base en Banco Mundial 2005 y CAN 2009.UNCTAD, (2011). 
El comercio solo desciende, producto de la denuncia del Acuerdo de Cartagena por parte de Venezuela en 2006, cuando el vecino país decidió retirarse de la CAN como respuesta a la negociación de los países de Colombia, Perú y Ecuador de comenzar negociones de los Tratados de Libre Comercio (TLC) con Estados Unidos. Entre otros, el retiro de Venezuela de la CAN, también se da en el marco de la solicitud de este mismo país p.200 de ingresar al Mercado Común Sur (Mercosur), como socio pleno en $2005^{4}$. Cabe agregar que en ambos casos, la institucionalidad de la CAN permite a los andinos negociar zonas de libre comercio con países de la región, como lo establece la propia normativa de ALADI, en los famosos acuerdos de alcance parcial y complementación económica $\mathrm{AAP}$ y $\mathrm{CE}$, que se conoce como el regionalismo abierto.

\subsection{El Sistema Andino de Integración (SAI)}

Fiel al artículo 48 del Acuerdo de Cartagena, la CAN se define como una organización subregional con personería jurídica internacional, compuesta por los Estados soberanos de Colombia, Perú, Ecuador y Bolivia y de los órganos e instituciones que conforman el denominado Sistema Andino de Integración (SAI).

La institucionalidad andina, ha evolucionado constantemente. En 1996 el Protocolo de Trujillo, que implica el compromiso de ir al mercado común, trajo beneficios para la integración toda vez que a la dinámica de acuerdos de los gobiernos, se crearon nuevos órganos para fomentar la participación empresarial y de otras organizaciones sociales en el proceso de integración regional. El SAI, le dio asiento institucional a los órganos como: los Consejos Consultivos Empresarial y Laboral, la Corporación Andina de Fomento (CAF), el Fondo Latinoamericano de Reservas (FLAR) y la Universidad Simón Bolívar, entre otros. Estos junto con las tradicionales como el Consejo Presidencial Andino, el Parlamentos Andino, el Consejo de Ministros de Relaciones Exteriores y la Secretaria de la Comunidad Andina, son las instituciones donde se desarrolla el marco legal de la CAN, o los avales para aumentar la certidumbre en los negocios (Figura 2).

\section{Figura 2. Comercio andino}

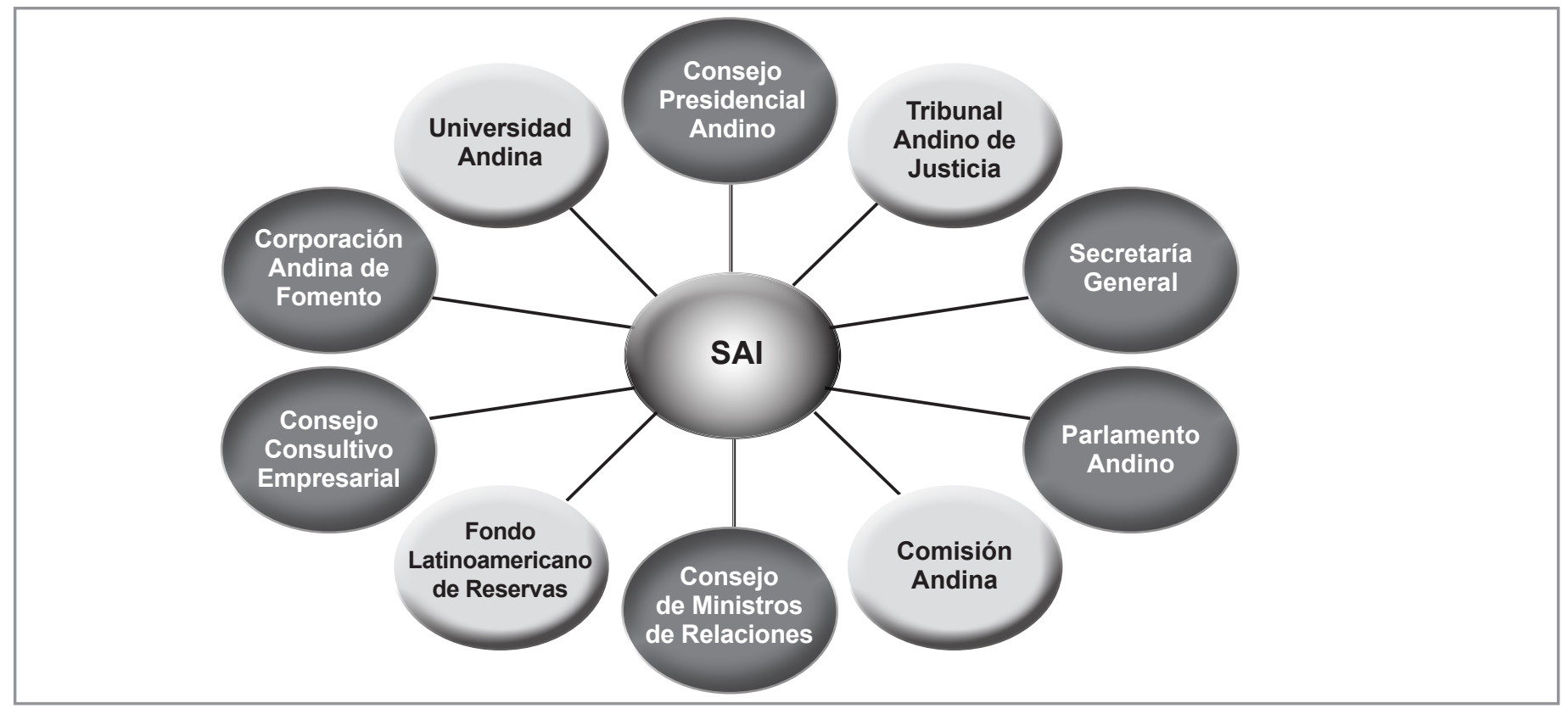

Fuente. Elaborado por el autor, con base en CAN (2010).

\footnotetext{
${ }^{4}$ Desde 1997, en el gobierno de Rafael Caldera, Venezuela quería pertenecer a Mercosur para reforzar sus acuerdos de complementación económica y energética con Brasil.

${ }^{5}$ Venezuela denunció el acuerdo de Cartagena en abril de 2006, y hoy por lo tanto no hace parte de la CAN.
} 
Los órganos de la CAN, salvo algunas diferencias en cuanto a administración y funciones, son comparables con la institucionalidad normativa y jurídica de la UE. En efecto y confirmando el postulado en torno a que los flujos de comercio y de inversiones necesitan de instituciones de tradición sólidas, que progresen en el marco normativo y den seguridad jurídica a los intercambios, la institucionalidad andina es muy parecida a la de la UE (Tabla 1).

Una pequeña descripción de la institucionalidad de la CAN, no sólo muestra la dedicación y competencias que tienen sus órganos para promover la integración económica, sino que en varios de ellos existe supranacionalidad jurídica para los intercambios. En efecto, la institucionalidad andina que ha sido un proceso de trasformación autónomo, se considera única en su género en América Latina, porque a la vez que ha copiado parte del ordenamiento institucional de la $\mathrm{UE}^{6}$, ha innovado para que otros actores, diferentes a los gobiernos, participen en la proyección de la integración, como lo son los empresarios, trabajadores y la propia sociedad civil.

La CAN, siendo fiel a los acuerdos de la asociación latinoamericana de integración ALADI, ha privilegiado la integración económica en la región, blindado los acuerdos tal cual se hace en la UE mediante actos jurídicos. (Grien, 1996).

Tabla 1. Comparación institucionalidad andina y europea

\begin{tabular}{|l|l|l|}
\hline \multicolumn{1}{|c|}{ Órganos } & \multicolumn{1}{|c|}{ Comunidad Andina } & \multicolumn{1}{c|}{ Unión Europea } \\
\hline Normativo & Comisión de la Comunidad Andina. & Comisión de la Unión Europea. \\
\hline Dirección política & $\begin{array}{l}\text { Consejo de ministros de relaciones exte- } \\
\text { riores de la Comunidad Andina. }\end{array}$ & Consejo de ministros de gobierno de la Unión Europea. \\
\hline Legislación & Consejo Comunidad Europea & Consejo Europeo \\
\hline Deliberación & Parlamento Andino & Parlamento Europeo \\
\hline Jurisdiccional & $\begin{array}{l}\text { Tribunal de Justicia de la Comunidad } \\
\text { Andina. }\end{array}$ & $\begin{array}{l}\text { Tribunal de Justicia de las Comunidades Europeas: CECA, } \\
\text { CEE, CEEA. }\end{array}$ \\
\hline Secretaria Ejecutiva & Secretaria de la Comunidad Andina & \\
\hline
\end{tabular}

Fuente. Elaboración propia del autor, con base en OMS y Comunidad Andina.

En la historia de la CAN, el órgano más importante de institucionalidad es el Consejo Presidencial Andino, que tiene como funciones emitir directrices sobre distintos ámbitos de la integración subregional, las cuales son instrumentadas por los órganos e instituciones del SAI. El Consejo Presidencial, propuso en 2003 por ejemplo, una integración más social, donde además de los intercambios, el comercio promoviera el desarrollo de las fronteras; en 2004, en Cochabamba, Bolivia, este órgano propuso la introducción de la cláusula democrática al interior del grupo, para lograr una mayor cohesión política y niveles de gobernabilidad consecuentes con la evolución de la integración. Entre 2005 y 2012, estos órganos se han dedicado a los temas de cadenas productivas regionales para transformar las ventajas comparativas en competitivas en todo el bloque (Cepal, 2013).

\subsection{Derecho comunitario andino y compara- ciones con la UE}

La institucionalidad andina se parece a la de la UE en lo que concierne al Consejo de Ministros, la Comisión y el Tribunal de Justicia, por sus conformaciones y sus funciones en materias propositivas, deliberantes y jurisdiccionales. En la CAN existe un órgano como la Secretaría General, que se ha mantenido a lo largo de los 43 años de integración. Este órgano se ha venido dotando de autonomía e independencia y se mantiene dentro de los de mayor reconociendo en la región y en el mundo, por su dinámica y sus resoluciones en procura de la integración plena de la CAN (Cepal, 2013).

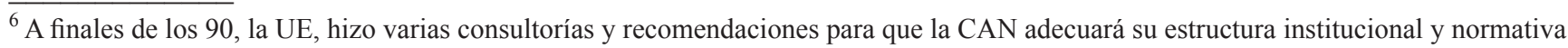
para lo que podría ser un acuerdo de libre comercio entre los dos bloques.
} 
La Secretaría General de la CAN, no se asemeja directamente a ninguna de las instituciones de la UE, es el órgano ejecutivo de la CAN, que a partir del 1 de agosto de 1997 asumió, entre otras funciones, las atribuciones de la Junta del Acuerdo de Cartagena; la resolución de asuntos sometidos a su consideración; la velación por el cumplimiento de los compromisos comunitarios y el mantenimiento de vínculos permanentes con los países miembros y de trabajo, con los órganos ejecutivos de las demás organizaciones regionales de integración y cooperación. Este órgano, está dirigido por un secretario general, elegido por consenso del Consejo Andino de Ministros de Relaciones Exteriores en reunión ampliada con la Comisión de la Secretaría General, la cual tiene capacidad propositiva y está facultada para formular propuestas de decisión al Consejo Andino de Ministros de Relaciones Exteriores y a la Comisión, así como iniciativas y sugerencias a la reunión ampliada del citado Consejo.
Sobre el anterior marco institucional, se ha construido el ordenamiento jurídico de la CAN, que está conformado por varios niveles y normas. El principal, dentro de la pirámide de Kelsen ${ }^{7}$ según el jurista Rodríguez (2005), es el que corresponde al conjunto de normas jurídicas comunitarias provenientes de la voluntad de los países miembros, contenidas en tratados constitutivos de la comunidad: Acuerdo de Cartagena, tratado de creación del Tribunal Andino de Justicia de la Comunidad Andina y Tratado Constitutivo del Parlamento Andino, con sus respectivos protocolos y modificaciones.

Las normas secundarias o de segundo nivel, provienen de las decisiones del consejo de ministros de relaciones exteriores y las decisiones de la Comisión Andina; luego en un tercer nivel, se pueden citar las resoluciones de la Secretaria General de la CAN; finalmente, los convenios de complementación industrial y otros que adopten los países miembros entre sí, en el marco del proceso de la integración subregional (Basombrio, 2005).

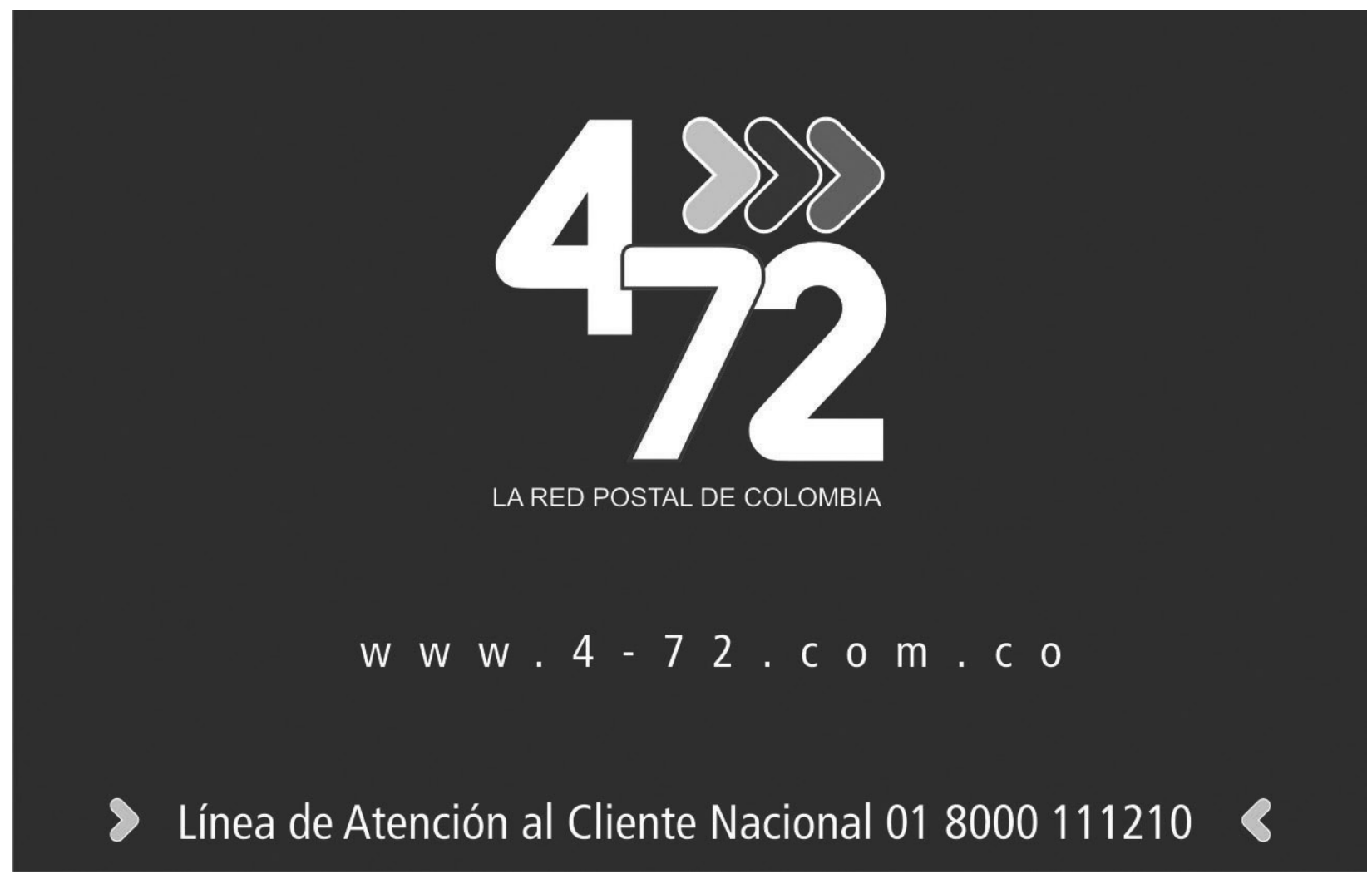

\footnotetext{
${ }^{7}$ Kelsen es llamado en Derecho Internacional, el fundador de la teoría pura de acuerdo a la concepción piramidal del derecho que pretendía dar un carácter de ciencia a la misma. La "piramide" de Kelsen, es una organización del Derecho, en el sentido de categorizar las normas desde un estado superior a otro inferior.
} 


\section{LA INTEGRACIÓN $y$ SUPRANACIONALIDAD ANDINA}

L a integración andina, ha evolucionado en su marco institucional y normativo porque los países, en sus constituciones políticas, han dejado claro los conceptos de integración y supranacionalidad, a la vez que

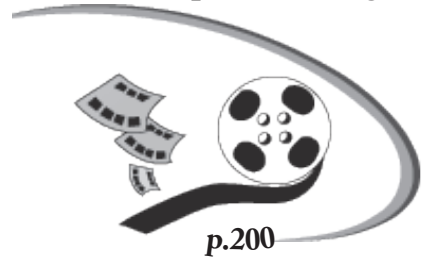

el Tribunal Andino de Justicia de la CAN, ha desarrollado los principios de aplicación inmediata, efecto directo y primacía del derecho comunitario; los acuerdos comerciales que garantizan estos principios, son los que han dado un margen de seguridad y confianza a empresarios e intercambios entre los países socios.

Para garantizar los beneficios que se pueden lograr de la globalización y la integración de los mercados, los economistas como Moncayo (2005) reconocen que es necesario avanzar en una base de política supranacional que lleve a coordinar esfuerzos que garanticen la seguridad y confianza de los acuerdos pactados; algunos analistas de derecho internacional como Molano (2002), señalan que la supranacionalidad debe conllevar a una verdadera unión política entre los participantes. En la CAN, los conceptos de integración regional y supranacionalidad de los órganos creados y de los acuerdos firmados, normas y disposiciones, están blindadas en las constituciones políticas de los países miembros en los temas económicos y comerciales, convirtiéndose en la primera instancia para consultar las preferencias y el interés de los países para realizar integración y ceder parte de su soberanía a órganos internacionales o comunitarios.
En efecto, se puede concluir que en la mayoría de los países andinos, las constituciones expresan categóricamente su convicción por el respeto al derecho internacional, la integración latinoamericana y el derecho comunitario andino. En Colombia, la constitución política de 1991 no sólo ratificó la supranacionalidad ${ }^{8}$, sino que estableció en su articulo 150, numeral 16 como función del Congreso la de "aprobar o improbar los tratados que el Gobierno celebre con otros Estados o con entidades de derecho internacional" (Constitución Política; casa de Nariño, 2010). Por medio de dichos tratados, podrá el Estado sobre bases de equidad, reciprocidad y conveniencia nacional, transferir parcialmente determinadas atribuciones a organismos internacionales que tenga por objeto promover o consolidar la integración económica con otros. El artículo 227, da preferencia a la integración regional afirmando que, "el Estado promoverá la integración económica, social y política con las demás naciones y especialmente con los países de América Latina y del Caribe, mediante la celebración de tratados que sobre bases de equidad, igualdad y reciprocidad, dando pie en el mismo a organismos supranacionales, inclusive para conformar una comunidad latinoamericana de naciones" (Constitución Política; casa de Nariño, 2010).

La constitución vigente de Ecuador de 1998, ratificando las constituciones de 1979 y de 1983, produjo un artículo exclusivo con principios integracionistas y comunitarios: "en el art.4 de dicho documento, se afirma que el Ecuador en sus relaciones con la comunidad internacional, propugna por la integración, de manera especial por la andina y latinoamericana". La Constitución Política

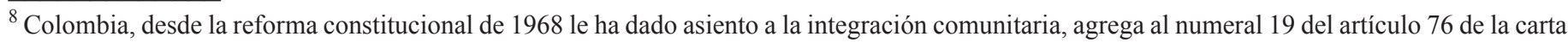
política, un inciso en el que dispone que, "Por medio de tratados o convenios aprobados por el Congreso, podrá el Estado obligarse para que sobre bases de igualdad y reciprocidad, sean creadas instituciones supranacionales que tengan por objeto promover o consolidar la integración económica con otros estados.

9 La Constitución Política de Ecuador de 1979, propugnaba por la solución de las controversias internacionales por métodos jurídicos y pacíficos y declarando que el Derecho Internacional es norma y conducta de los Estados en sus relaciones reciprocas. En la reforma de 1983, Ecuador estableció igualmente el fortalecimiento de la Comunidad Internacional y de sus organismos, califica la integración iberoamericana como un sistema eficaz para alcanzar el desarrollo de la comunidad de los pueblos unidos, de solidaridad; de manera concreta, en el inciso tres dice que Ecuador podrá formar con uno o más Estados, asociaciones para la promoción de la defensa de los intereses nacionales y comunitarios.
} 
de Perú de 1993, contempla en su artículo 44 entre los deberes primordiales del Estado, el de establecer y ejecutar la política de fronteras y promover la integración, particularmente latinoamericana. Finalmente, pese a haber denunciado el tratado de la Comunidad Andina en 2006, la constitución de Venezuela de 1999 en su preámbulo, afirma que "el pueblo de Venezuela, promoverá la cooperación pacifica entre las naciones e impulsará y consolidará la integración Latinoamérica de acuerdo a los principios de no intervención y auto determinación de los pueblos ${ }^{10}$.

Bolivia es el único país de la CAN, que no ha adaptado completamente los principios del Acuerdo de Cartagena e Integración y Supranacionalidad en su constitución política; sin embargo, las normas constitucionales utilizadas en ese país para suscribir y poner en vigor los referidos acuerdos, incluyendo al Tribunal de Justicia, son las normales que disciplinan los temas de las relaciones internacionales y de la suscripción de tratados públicos ${ }^{11}$.

\subsection{Tribunal Andino de Justicia y los prin- cipios normativos comunitarios}

Como ya se afirmó en el acápite anterior, el Tribunal de Justicia de la Comunidad Andina (TAJ), es el órgano jurisdiccional del grupo que garantiza el cumplimiento de las normas al interior del bloque; dentro de sus funciones más importantes, está el desarrollo de los principios de supranacionalidad dentro de su propia constitución. El TAJ, fue incorporado al Sistema Andino en 1979; está integrado por cinco magistrados, un representante por cada país miembro. Las competencias del Tribunal, se ejercen sobre todo el territorio de los cuatro países y su sede está en Quito (Kaune, 2005).

Controla la legalidad de las normas comunitarias mediante la acción de nulidad, e interpreta las normas que conforman el Ordenamiento Jurídico de la CAN y dirime controversias.
Mediante el Protocolo Modificatorio del Tratado de Creación del Tribunal de Justicia de la CAN, aprobado en mayo de 1996 y que entró en vigencia en agosto de 1999, se asignó a este órgano del SAI nuevas competencias, entre ellas: el Recurso por Omisión o Inactividad, la Función Arbitral y la de Jurisdicción Laboral. Su nuevo estatuto, que actualiza y precisa los procedimientos que se desarrollan ante ese Tribunal, fue aprobado el 22 de junio del 2001 por el Consejo Andino de Ministros de Relaciones Exteriores.

El TAJ, garantiza la aplicación de las normas comunitarias y la supranacionalidad de la Comunidad Andina con los principios de aplicación inmediata, efecto directo y prima-cía, con los que ha sido provisto su articulado. La aplicación inmediata y el efecto directo, están legitimados en el artículo dos del Tratado del TAJ vigente y en el Protocolo de Cochabamba, modificatorio de dicho tratado de 1999, que dispone que "las decisiones obligan a los Países Miembros desde la fecha en que sean aprobadas por la Comisión, adoptar las normas comunitarias" (Tribunal Andino Justi-cia, Comunidad Andina, 2007). Por su parte, el artículo tres establece que "las decisiones de la Comisión serán directamente aplicables en los Países Miembros a partir de la fecha de su publicación en la Gaceta Oficial del Acuerdo, a menos que las mismas señalen una fecha posterior". Así, las leyes comunitarias no requieren de procedimientos de recepción en el ordenamiento interno de los Países Miembros para surtir todos sus efectos.

Las normas andinas son de obligatorio e inmediato cumplimiento por los Países Miembros en todas sus instancias, por los órganos de la CAN y los particulares. Lo anterior, también significa que la normativa andina, obliga a todos los poderes de los Estados, sin distinción en todo su territorio, sin limitaciones de orden estatal, regional o municipal (Tribunal Andino Justicia, Comunidad Andina, 2005). Es claro entonces, que el ciudadano común adquiere

\footnotetext{
${ }^{10}$ Precisa en el artículo 153, que la República promoverá y favorecerá la integración latinoamericana, en aras de avanzar hacia la creación de una comunidad de naciones, defendiendo los intereses económicos, sociales, culturales, políticos y ambientales de la región, además de establecer que las normas que se adopten en el marco de los acuerdos de integración serán consideradas parte integrante del ordenamiento legal vigente y de aplicación directa y preferente a la legislación interna.

${ }^{11}$ El artículo 59, afirma que son atribuciones del poder legislativo numeral 12, aprobar los tratados, concordatos y convenios internacionales y el 96 afirma que son atribuciones del Presidente de la República numeral 2 negociar y concluir tratados con naciones extranjeras, canjearlos, previa ratificación del Congreso.
} 
obligaciones y derechos comunitarios, cuyo cumplimiento puede exigir, tanto ante sus Tribunales Nacionales, como ante las instancias administrativa y judicial comunitarias (efecto directo).

El principio de la preminencia, conlleva la virtud que tiene el ordenamiento comunitario, de ser imperativo y de primar sobre una norma de derecho interno; allí, donde se trate de aplicar normas legales en actos jurídicos contemplados en el derecho de integración, deberá acudirse al ordenamiento comunitario con prevalencia sobre el derecho interno, llámese ley, reglamento o decreto (Basombrio, 2005). El concepto de preeminencia, también está ratificado en la creación del TAJ, en el mismo capítulo dos, el cual señala que la normativa andina prevalece en su aplicación sobre las normas internas o nacionales (Tribunal de Justicia Andino, Comunidad Andina, 2007). El mismo Tribunal en la Sentencia del Proceso 3-AI-96, señala que el ordenamiento comunitario prima sobre una norma de derecho interno que se le oponga, cualquiera sea el rango de esta última. Cuando se presente un conflicto entre las normas nacionales de los Países Miembros y las normas comunitarias, estas últimas se aplican con preferencia a las primeras. Este principio de primacía de las normas comunitarias, permite que los Países Miembros no puedan alegar normas de su derecho interno para dejar de cumplir sus obligaciones adquiridas en el marco del proceso de integración.

Una norma andina, sólo puede ser modificada por otra norma andina emitida por los correspondientes órganos comunitarios y no por los poderes legislativos de los Países Miembros. Ello por supuesto, no impide el desarrollo de una ley comunitaria a través de la legislación nacional, esto únicamente, cuando sea necesaria para la correcta aplicación de la comunitaria (Basombrio, 2005).

\subsection{Funciones del TAJ}

Adicionalmente, desde 1999 para mejorar la institucionalidad jurídica andina, se dotó al TAJ de nuevos instrumentos para que avanzará en sus funciones jurisdiccionales como fueron
(Sierralta, 2005): acción por incumplimiento, mecanismo jurídico que posibilita al TAJ aplicar el cumplimiento de las normas que conforman el ordenamiento jurídico comunitario. Esta misma acción, garantiza la observancia de los objetivos del proceso de integración, mediante la verificación de comportamientos, respecto a los compromisos que han asumido los miembros en el Acuerdo de Cartagena; con este instrumento el TAJ dicta sentencia a los Estados incumplientes; el Estado incumpliente debe adoptar, conforme a lo previsto en el artículo cuatro del tratado del TAJ, las medidas necesarias para poner fin al incumplimiento; caso contrario, a través de un procedimiento sumario, se le impondrá las sanciones previstas en el tratado de creación del tribunal (Tangarife, 2005).

Otro instrumento jurídico del TAJ, es el de acción de nulidad que lo faculta para ejercer el control de la legalidad de la normativa comunitaria y de los actos de las Instituciones Comunitarias. De esta manera, el TAJ puede incoar a los Países Miembros, al Consejo de Ministros de Relaciones Exteriores, la Comisión, la Secretaria General o las personas naturales o jurídicas afectadas en sus derechos subjetivos o intereses legítimos, a fin de obtener la nulidad de las decisiones del Consejo de Ministros de Relaciones exteriores, de la Comisión, de las resoluciones de secretaria y de los convenios a que refiere el literal "e" del artículo primero del Tratado, dictados o acordados con violación de las normas que conforman el ordenamiento jurídico de la CAN, incluso por desviación del poder (Tangarife, 2005) .

Finalmente, la interpretación prejudicial persigue que todos los Países Miembros tengan un igual entendimiento del sentido y alcance de la norma comunitaria, a fin de que se logre su aplicación uniforme en los países miembros. Según el tratadista Guy Isaac, la interpretación "constituye un mecanismo de cooperación judicial por el cual el órgano jurisdiccional nacional y el Tribunal de Justicia, en el orden de sus propias competencias, son llamados a contribuir directa y recíprocamente en la elaboración de una decisión" (Basombrio, 2005) ${ }^{12}$.

\footnotetext{
${ }^{12}$ Según el propio Tangarife, el recurso por omisión, faculta al tribunal a compeler al órgano incumpliente, para que adopte la conducta señalada por ley, a fin de hacer cesar su inactividad.
} 


\subsection{Efectividad del Tribunal Andino de Justicia}

Varios analistas andinos, han señalado como inconveniente para superar la etapa del arancel externo común y proyectar la integración al Mercado Común, los incumplimientos que los países miembros de la CAN han tenido a los fallos y la demora proferidos por dicho órgano (García, 2005). Sin embargo, es necesario hacer una evaluación de lo que ha ocurrido en el período 1990 y 2010, para determinar hasta qué punto el órgano de TAJ está generando confianza y cumpliendo con sus funciones y sus decisiones, en los negocios internacionales.

Tabla 2. Controversias CAN 1989-2009

\begin{tabular}{|c|c|c|c|c|c|}
\hline & Controversias & Dictámenes & Ante la SGCA & $\begin{array}{c}\text { Incumplimiento a } \\
\text { TAJ }\end{array}$ & Sentencias TAJ \\
\hline $80-89$ & 34 & 34 & 0 & 1 & 0 \\
\hline $90-99$ & 183 & 177 & 87 & 29 & 16 \\
\hline 2000 & 34 & 38 & 20 & 22 & 12 \\
\hline 2001 & 27 & 21 & 10 & 7 & 11 \\
\hline 2002 & 24 & 22 & 9 & 5 & 7 \\
\hline 2003 & 31 & 27 & 14 & 9 & 3 \\
\hline 2004 & 20 & 28 & 10 & 4 & 2 \\
\hline 2005 & 23 & 18 & 8 & 6 & 2 \\
\hline 2006 & 12 & 15 & 4 & 1 & 13 \\
\hline 2007 & 4 & 9 & 1 & 0 & 0 \\
\hline 2008 & 2 & 1 & 1 & 0 & 0 \\
\hline Total & 394 & 391 & 164 & 84 & 67 \\
\hline
\end{tabular}

Fuente. Elaboración propia del autor, con base en datos integrados de Controversias Comerciales de América Latina y el Caribe, Badicc, Cepal (2011).

Se puede concluir, que realmente el sistema jurisdiccional de la CAN está funcionando correctamente, a la vez que está siendo utilizado por los países miembros (Tabla 2). Cabe señalar, que las controversias entre 1989 y 2008 que se presentaron en la CAN, llegaron a 394 casos de los cuales en 391 se produjeron los dictámenes respectivos. En la acción prejudicial o consulta de casos al TAJ, se realizaron 84. Es bien interesante esta cifra, porque si se compara con el número de procesos generados (67 sentencias), se tendría que sólo el $15 \%$ de todas las posibles infracciones a la normativa andina por los países miembros, se vuelven demandas concretas. Esto permite aseverar que las consultas al TAJ, no solo han sido resueltas por este ente, sino más importante en esta instancia, sus recomendaciones han satisfecho a los consultantes y de esta manera, no han tenido que acudir a los procesos comunitarios judiciales.

Donde sí hay problemas y bien cabría proponerinstru-mentos que flexibilicen el sistema de controversias, está en el hecho que los países en su gran mayoría no acatan inmediatamente los fallos del TAJ; una causa de los incumplimientos como se señaló al comienzo, es que la etapa jurisdiccional del proceso por incumplimiento está durando en el TAJ entre 12 y 15 meses, lapso considerado como muy largo, por los costos para los empresarios y sobre todo, para las retaliaciones que deben aplicar las naciones por los incumplimientos de los países violadores del derecho comunitario. 


\section{CONCLUSIONES}

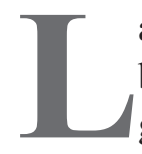

a CAN, posee un patrimonio institucional preestablecido, con un orden jurídico autónomo que le garantiza al grupo la supranacionalidad y por lo tanto, la capacidad de contratación internacional Treaty Making Power. No obstante, el incumplimiento por parte de algunos países a los fallos del TAJ, puede presentarse como modelo propio y original en materia de derecho comunitario, que avanza para darle mayor seguridad jurídica a los negocios y la integración andina.

El crecimiento del comercio de bienes que se ubicó en US $\$ 10.000$ millones en 2012, no solo es uno de los más dinámicos de la región que ha respondido, entre otros elementos, a la vecindad, el tratado preferencial, sino más importante a las bases institucionales que se han creado en la CAN. La Secretaría y el Tribunal de Justicia de la
Comunidad Andina, no solo han garantizado los principios de la normativa, sino que también han logrado solucionar más de 400 controversias entre los socios en los últimos 20 años; incluso es el único bloque que no ha tenido que recurrir a la OMC para que ella sirva de mediador.

La CAN y su TAJ, deben ser ejemplo de institucionalidad para continuar trabajando y promoviendo la integración latinoamericana; precisamente hoy, en el contexto de integración de la Unión de Naciones del Sur (UNASUR), se ubica al TAJ como el órgano capaz de asumir la función jurídica de este proyecto regional. En este sentido, el Tribunal Permanente de Revisión del Mercosur, creado por el Protocolo de Olivos en 2002, está insistiendo en practicar las ejecutorías del TAJ para que, sobre la base de este último, se conforme un único tribunal para aumentar la institucionalidad y supranacionalidad de la región. 


\section{REFERENCIAS}

Basombrio, I. (2005). Integración andina: instituciones y derecho comunitario, CAN.

Beckerman, P. (2005). Andean Exchanges-rate regímenes, 1994-2003: a Brieffor 'Stable but Flexible Regimenes", Series Macroeconomía del Desarrollo 34, CEPAL: Santiago de Chile.

Beltran, L. (2008). Colombia y Venezuela en los nuevos ejes de integración Hemisférica, Unisalle 2008.

Beltran, L. (2006). Comercio colombo-venezolano a elegir entre la zona de libre comercio y el Mercado Común, en Cinep, julio 2006 .

Beltran, L. (2009).Tesis Doctoral: Ventajas comparativas y competitivas en la integración colombo-venezolana, cadenas productivas conjuntas, las exportaciones a Estados Unidos y Brasil; UAM, 2009.

Beste, M. (2004). Regional Integration and National Adaptation: Some Observations from European Experiences, CAN.

BID (2005), Integration and trade in the Americas: A preliminary Estimate of 2004 trade, Washington D.C.

Cámara Colombo Venezolana (2005), Covenotas, Bogotá 2005.

CAN (2007). 38 años de integración económica y comercial. Lima, Perú.

CEPAL (2012). Panorama de la inserción internacional de América Latina y el Caribe 2011-2012 y espacios de cooperación regional.

CEPAL (2013) BADICC. Base de datos integrada de Controversias Comerciales de América Latina y el Caribe.

Grien, R. (1996). La Integración económica como alternativa inédita para América Latina, FCE, México D.C

Kaune, Arteaga W. (2005) Noción de la Integración y el Orden Jurídico Comunitario, CAN, 2005

Kassim, A. (2003). European Integration since the 1990s: Member States and the European Commission”, Paper prepared for ARENA Seminar, University of Oslo, 4 November, Comunidad Europea, 2003

Moncayo E. (1999) Las relaciones externas de la comunidad Andina; entre la globalización y el regionalismos abierto, $C A N$.

Molano, A. (2002) Derecho Internacional Público, Bogotá, G\&B Graphic.

Presidencia de La República de Colombia (2011). Constitución Política. 
Rodríguez, I. (2005). La experiencia Europea en la aplicación judicial del Derecho Comunitario, libro la Integración del Derecho Comunitario y el Pacto Andino-Universidad Simón Bolívar, Venezuela 1997S.

Sierralta, A. (2005). Los mecanismos de solución de controversias en la Comunidad Andina de Naciones: desarrollo, tendencias y los desafios del comercio internacional, Cepal.

Secretaría General de la Comunidad Andina. (1997). Acuerdo de Cartagena. Recuperado de http://www.comunidadandina. org/public/libro_13.htm

Tangarife, M. (2005) Sistema Jurisdiccional en el Proceso Andino, CAN.

Vieira, E, (1999) El mercado ampliado andino: una realidad, Cámara de Comercio de Bogotá.

Thompson, L., y Nadler, J. (2002). Negotiation via information technology: Theory and application. Journal of Social Issues, 58(1), 109-124.

Vickery, G., y Wunsch-Vincent, S. (2009). RyD Innovation in ICT Sector: Toward Globalization and Collaboration. En W. E. Forum, The Global Information Technology Report (pp. 95-109). Geneva, Switzerland: World Economic Forum Editors.

Yoguel, G. (2008). Información y Conocimiento: Las Vinculaciones entre Difusión de TIC y Competencias Tecnológicas. En G. Valenti, D. Avaro, y M. Casalet (Eds.), Instituciones, sociedad del conocimiento y mundo del trabajo (pp. 295326). México: FLACSO.

Zuboff, S. (1988). In the age of the smart machine: the future of work and power. New York: Butterworth-Heinemann. 
